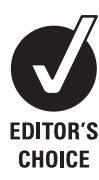

CHOICE

\title{
Does socioeconomic status fully mediate the effect of ethnicity on the health of Roma people in Hungary?
}

\author{
Z Vokó, ${ }^{1}$ P Csépe, ${ }^{2}$ R Németh, ${ }^{3}$ K Kósa, ${ }^{1}$ Z Kósa, ${ }_{1}^{4}$ G Széles, ${ }^{1}$ R Ádány ${ }^{1,5}$
}

\begin{abstract}
${ }^{1}$ Department of Preventive Medicine, Faculty of Public Health, Medical and Health Science Centre, University of Debrecen, Hungary;

${ }^{2}$ Department of Public Health,

Faculty of Medicine,

Semmelweis University,

Budapest, Hungary; ${ }^{3}$ National

Centre for Healthcare Audit and Inspection, Budapest, Hungary;

${ }^{4}$ Department of Health Visitor Methodology and Public Health, Faculty of Health, Medical and Health Science Centre,

University of Debrecen, Hungary;

${ }^{5}$ Public Health Research Group of the Hungarian Academy of

Sciences, at the Medical \&

Health Science Center,

University of Debrecen,

Debrecen, Hungary
\end{abstract}

Correspondence to:

Z Vokó, Division of Biostatistics

\& Epidemiology, Department of

Preventive Medicine, Faculty of

Public Health, Medical and

Health Sciences Centre,

University of Debrecen, $\mathrm{H}-4028$

Debrecen, Kassai út 26/b,

Hungary; z.voko@sph.dote.hu

Accepted 18 January 2009

\begin{abstract}
Background: Several models have been proposed to explain the association between ethnicity and health. It was investigated whether the association between Roma ethnicity and health is fully mediated by socioeconomic status in Hungary.
\end{abstract}

Methods: Comparative health interview surveys were performed in 2003-04 on representative samples of the Hungarian population and inhabitants of Roma settlements. Logistic regression models were applied to study whether the relationship between Roma ethnicity and health is fully mediated by socioeconomic status, and whether Roma ethnicity modifies the association between socioeconomic status and health.

Results: The health status of people living in Roma settlements was poorer than that of the general population lodds ratio of severe functional limitation after adjustment for age and gender 1.8 (95\% confidence interval 1.4 to 2.3)). The difference in self-reported health and in functionality was fully explained by the socioeconomic status. The less healthy behaviours of people living in Roma settlements was also related very strongly to their socioeconomic status, but remained significantly different from the general population when differences in the socioeconomic status were taken into account, leg odds ratio of daily smoking 1.6 (95\% confidence interval 1.3 to 2.0 ) after adjustment for age, gender, education, income and employment).

Conclusion: Socioeconomic status is a strong determinant of health of people living in Roma settlements in Hungary. It fully explains their worse health status but only partially determines their less healthy behaviours. Efforts to improve the health of Roma people should include a focus on socioeconomic status, but it is important to note that cultural differences must be taken into account in developing public health interventions.

The association between ethnicity and health is well established. Though it is generally accepted that interpreting ethnicity as an independent determinant of health is a simplification, present knowledge of the complex causal network of ethnicity, socioeconomic status (SES), health behaviour, environment and health status is rather limited. ${ }^{1}$

The majority of studies on ethnicity and health have been published in the USA since the beginning of the twentieth century (comparing health and health determinants in white people, AfricanAmericans, Hispanics and Native Americans), ${ }^{2-6}$ and in Britain (study on indigenous population and different ethnic minorities like Asian, Indian etc)..$^{8}$ Data on the health status and its determinants of the Roma population living in CentralEastern Europe are scarce, despite the fact that they are the largest minority in the European Union, particularly in Bulgaria, Romania, Hungary, the Slovak and the Czech Republic. ${ }^{9-11}$ Of the small number of studies in this population, the majority were conducted on convenience samples and methodological problems frequently occurred. Data protection laws in these countries present a significant obstacle in designing and conducting state of the art epidemiological studies in this field. ${ }^{12}$ Nevertheless, available data show that Roma people have much worse health status, exhibit much less favourable health behaviour and live in an unhealthier environment than the average population. ${ }^{13}$ Recently, the results of two comparative health surveys of the general Hungarian adult population and of the inhabitants of Roma settlements were reported. ${ }^{14}$ It was found that the health status of people living in Roma settlements was poor and comparable to the health status of people in the lowest socioeconomic quartile of the general population. The data suggested that the lifestyle of people living in Roma settlements is even less conducive to future health than that of the poorest of the general population.

However, the influence of Roma ethnicity on health and health behaviours remains unknown. As has already been pointed out: 'Studies that inadequately account for socioeconomic circumstances when examining ethnic-group differences in health can reify ethnicity (and its supposed correlates); however, the reductionist attribution of all ethnic differences in health to socioeconomic factors is untenable. The only productive way forward is through studies that recognize the contingency of the relations between socioeconomic position, ethnicity, and particular health outcomes. ${ }^{\prime 15}$ Using data from the National Health Interview Survey 2003 and the Roma Health Survey, it was possible to investigate whether the effect of Roma ethnicity on health is fully mediated by socioeconomic status and whether Roma ethnicity modifies the strength of the association between socioeconomic status and health.

\section{METHODS}

The design of the Hungarian National Health Survey 2003 and of the Roma Health Survey has already been reported. ${ }^{14}$ Briefly, the National Health Survey was based on a representative sample of the non-institutionalised Hungarian adult population, and collected information on self-reported health status, as well as on the main behavioural and socioeconomic determinants of health. ${ }^{16}$ The study population of the National 
Health Survey was randomly selected from the Central Data Processing, Registration and Election Office's registry using two-stage sampling. In the first stage, communities (cities, towns and villages) were stratified by county and by community size. Within counties, communities were chosen with a sampling probability proportional to size. Individuals were then selected at random from the selected communities. To maximise the cost-effectiveness of the field work, a minimum of 10 individuals was chosen from each community selected. Of the planned 7000 interviews in the National Health Interview Survey, 5072 were completed. Fifteen per cent of participants selected could not be located during the period of field work, $8 \%$ refused to participate, and $4 \%$ were unable to participate for other reasons.

The Roma Health Survey collected the same information based on a representative sample of persons living in Roma settlements in the north-eastern part of Hungary, where the representation of Roma people is the highest in the country. The settlements were mapped previously and this served as the basis for the health survey. A two-stage sampling process was employed. First settlements were selected randomly, and then households were selected using the random walk method, based on a map of the settlement. All adults in the household selected were interviewed by the interviewers. Of the planned 1000 interviews 969 were completed successfully, 12 persons refused to participate and 19 interviews were incomplete $(96.9 \%$ response rate). Given the low number of elderly persons in the Roma Health Survey, the analysis was limited to persons aged 18-64 years, reducing the sample size to 936 persons in the Roma Health Survey and 4121 individuals in the National Health Survey.

Both surveys were approved by the Ethical Committee of the Hungarian National Scientific Council on Health.

The questionnaires used in the two surveys were almost identical, allowing merger of the datasets and multiple regression models fit to study the details of the associations between ethnicity, socioeconomic factors and health. ${ }^{17}$ Two dimensions of health were investigated: health status and health behaviour. Health status was characterized by selfreported health and functional limitations, whereas health behaviour was represented by smoking, consumption of fresh fruits and vegetables, and types of fat used for cooking.

Specifically, self-reported health was assessed using a standard single-item measure (How is your health in general?) with five response options recommended by the WHO to measure perceived health. ${ }^{18}$ The response categories good, very good and fair were combined, as were bad and very bad. Functional limitation was assessed by a single-item question 'Do you have any complaints, injuries, diseases that limit your everyday activities, such as working, shopping, managing your life, playing sports or keeping contact with other people?' The answers - 'Yes I do, I am severely limited in my daily activities'; 'Yes I do, I am moderately limited in my daily activities'; 'No, I do not' - were dichotomised for the analysis to either severe functional limitation or modest or no limitation. Smoking was measured using the instrument recommended by the EUROHIS project of the WHO for population surveys. ${ }^{18}$ Questions in the instrument ascertained whether or not someone smoked, and if yes, what. Cigarette smokers were asked about the frequency of smoking, and daily smokers were asked about the number of cigarettes smoked per day. Smoking habit was dichotomised for the regression analysis as daily smokers and others. Consumption of fresh fruits and vegetables, use of different types of fat for cooking, date of birth, gender, education, employment and monthly household income were assessed by direct questioning. Consumption of fresh fruits and vegetables was dichotomised as less than weekly and more frequently, and use of different types of fat for cooking was dichotomised as use of only lard and other. Age was categorised as 18-29, 30-44 or 45-64 years old. Education level was categorised as only primary education, secondary education without leaving certificate and at least secondary education with leaving certificate. Employment was categorised as active worker, unemployed, pensioner, disability pensioner, and other inactive. Mean household equivalent monthly income was used in the analysis, calculated as the total household income per month divided by the square root of the number of persons in the household. This adjustment was necessary because the income required to provide the same living standards does not increase linearly as the number of people in a household increases. As ethnicity was not explicitly requested in the surveys it was assumed that all participants of the Roma Health Surveys were Roma.

The theoretical model investigated is shown in figure 1.

- i) The solid arrows represent the simplest pathway: socioeconomic status fully mediates the association between Roma ethnicity and health (full mediation model).

- ii) The dashed arrows add another layer of complexity: socioeconomic status partially mediates the association between Roma ethnicity and health (partial mediation model).

- iii) Dotted arrows reflect the hypothesis that Roma ethnicity is not only a determinant of health but also modifies the association between socioeconomic status and health (effect modification model). ${ }^{19}$

Logistic regression models were fit in a stepwise manner to determine which model the data support.

First, logistic models were fit with self-reported health, functional limitation, smoking, consumption of fresh fruits and vegetables, and using only lard as fat for cooking as outcome variables, and living in Roma settlement as independent variable corrected for age and gender. Next, in each model income, education and employment were added one by one. Finally, full models were fit with interaction terms between the variables 'living in Roma settlement' and the SES variables. The Wald-test was applied to test the hypotheses of no interaction; $\mathrm{p}<0.01$ was considered statistically significant.

\section{RESULTS}

\section{The mediation models for health status}

Table 1 shows that both self-reported health and functional limitation were strongly related to socioeconomic factors. The odds of reporting very bad or bad health was 2.2 (95\% confidence interval (CI) 1.8 to 2.7) times higher among people who lived in Roma settlements than in the general population after adjustment for age and gender (figure 2). As the figure shows, this association gradually disappears after adjustment for income and education. The relationship between Roma ethnicity and functional limitation was similar; the effect disappeared after adjustment for income (figure 2).

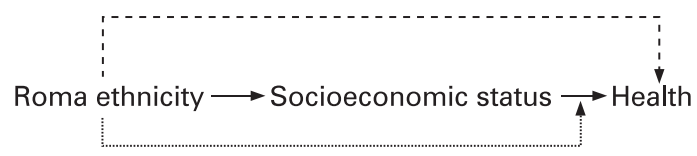

Figure 1 The theoretical model investigated in the study. 

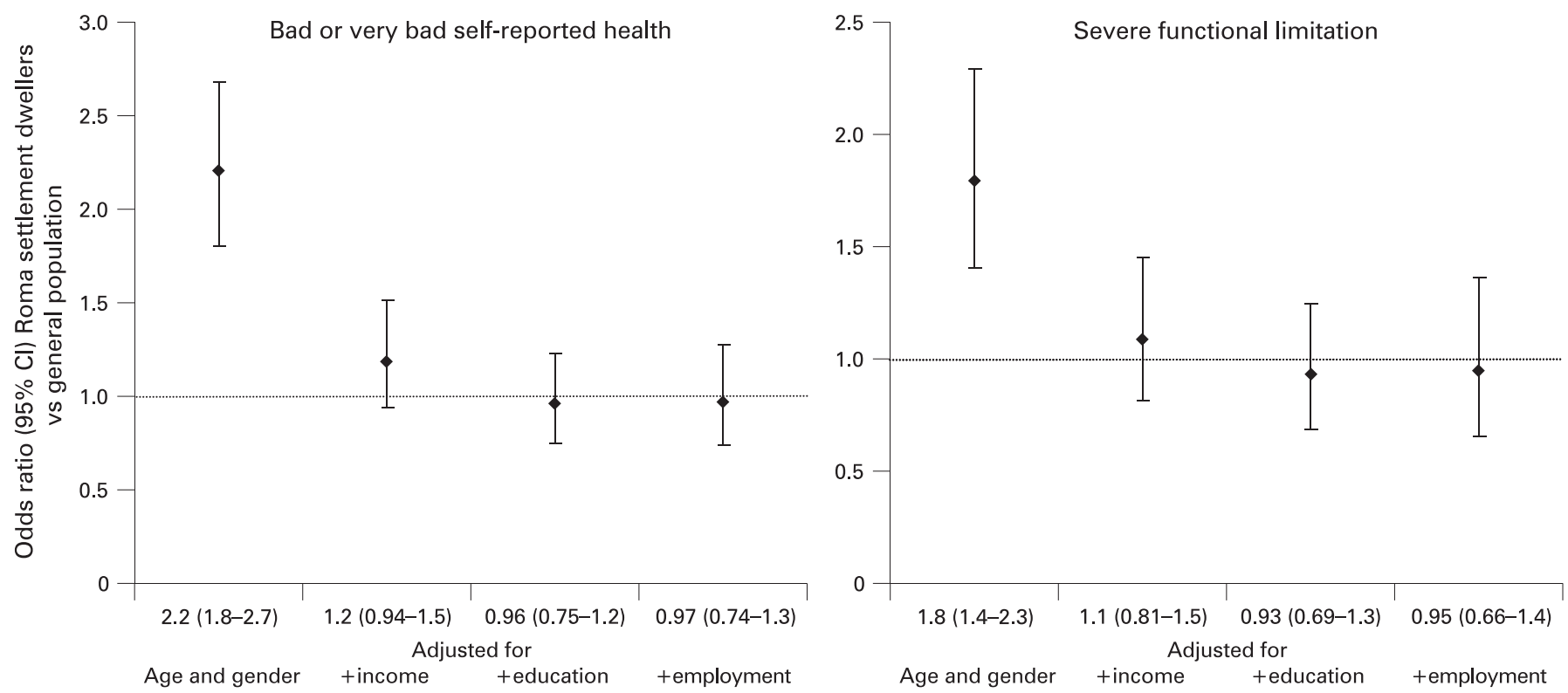

Figure 2 The association between Roma ethnicity and health status. Cl, confidence interval. Self-reported health was dichotomised as bad, or very bad and satisfactory, good or very good; functional limitation as severe functional limitation, or modest or no limitation. The dotted line represents an odds ratio of 1 , which corresponds to no association.

\section{The mediation models for health behaviour}

Just like health status, health behaviour was also strongly related to socioeconomic factors (table 2). The odds of daily smoking, consuming fresh fruits less than weekly and using only lard as fat for cooking were much higher among those who lived in Roma settlements (figure 3). The odds ratios were reduced, but remained statistically significant after adjustment for income, education and employment.

\section{The effect modification models}

Only two associations were found between socioeconomic factors and health that were modified by Roma ethnicity. Income was very strongly associated with daily smoking and non-consumption of fresh fruits and vegetables among people living in Roma settlements. A $40 €(\sim 62 \$)$ increase in the household equivalent monthly income reduced the odds of daily smoking by $6 \%$ in the general population, and by $16 \%$ among people living in Roma settlements; odds ratio (OR) 0.94 (95\% CI
0.92 to 0.97 ) and 0.84 (95\% CI 0.76 to 0.92 ). Similarly, a $40 €$ increase in the household equivalent monthly income reduced the odds of consuming fresh fruits or vegetables less than weekly by $5 \%$ in the general population, and by $22 \%$ among people living in Roma settlements; OR 0.95 (95\% CI 0.87 to 1.03 ) and 0.78 (95\% CI 0.69 to 0.88 ).

\section{DISCUSSION}

The present study found that socioeconomic status is strongly related to health status and health behaviour in people living in Roma settlements. Results show that the differences in health status (as measured by self-reported health and functional limitation) between the general population and people living in Roma settlements are fully explained by the differences in income, education and employment. However, the differences in health behaviour (notably smoking, consumption of fruits and vegetables, and type of fat used for cooking) could not be accounted for by socioeconomic factors alone, leaving room for

Table 1 The association between socioeconomic status, Roma ethnicity and health status

\begin{tabular}{|c|c|c|}
\hline & \multicolumn{2}{|l|}{ Odds ratio* $(95 \% \mathrm{Cl})$} \\
\hline & Bad or very bad self-reported health & Severe functional limitation \\
\hline Equivalent monthly income $\dagger$ & $0.90(0.85$ to 0.94$)$ & $0.92(0.87$ to 0.98$)$ \\
\hline \multicolumn{3}{|l|}{ Education } \\
\hline Primary only & 1.0 (reference) & 1.0 (reference) \\
\hline Secondary without leaving certificate & $0.91(0.69$ to 1.2$)$ & $0.83(0.59$ to 1.2$)$ \\
\hline $\begin{array}{l}\text { At least secondary education with leaving } \\
\text { certificate }\end{array}$ & $0.49(0.37$ to 0.64$)$ & $0.74(0.53$ to 1.0$)$ \\
\hline \multicolumn{3}{|l|}{ Employment } \\
\hline Active worker & 1.0 (reference) & 1.0 (reference) \\
\hline Unemployed & $1.6(0.99$ to 2.7$)$ & 1.3 (0.66 to 2.7$)$ \\
\hline Pensioner & 6.5 (4.8 to 8.9 ) & 12.7 (8.8 to 18.2 ) \\
\hline Disability pensioner & $1.5(1.1$ to 2.1$)$ & $2.1(1.4$ to 3.1$)$ \\
\hline Other inactive & $1.5(1.0$ to 2.2$)$ & $1.8(1.1$ to 2.9$)$ \\
\hline Living in Roma settlements & $0.97(0.74$ to 1.3$)$ & 0.95 (0.66 to 1.4$)$ \\
\hline
\end{tabular}

$\mathrm{Cl}$, confidence interval.

*Estimates from a logistic regression model containing all factors and adjusted for age and gender.

$\uparrow$ Per $40 €$. 


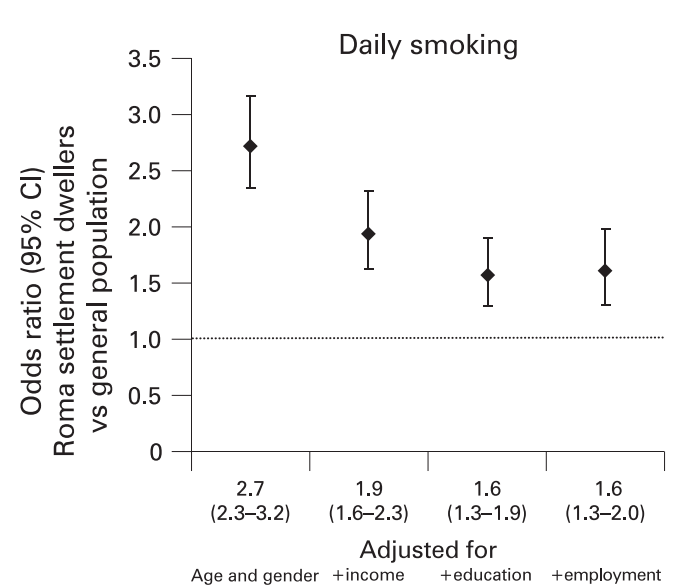

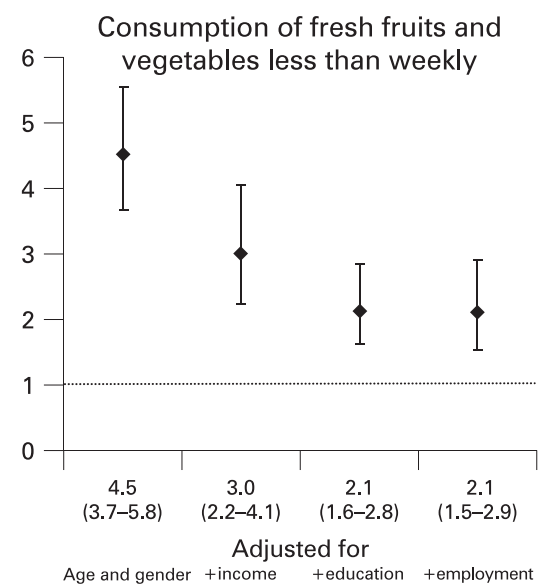

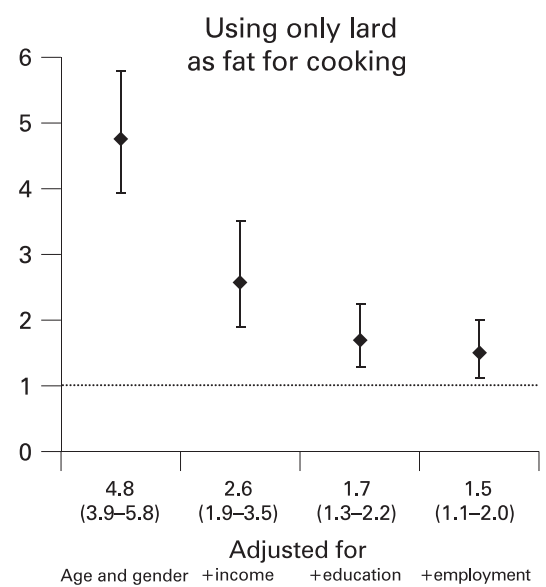

Figure 3 The association between Roma ethnicity and health behaviour. Smoking was dichotomised as daily smoker and other, consumption of fresh fruits and vegetables as less than weekly and other, and types of fat used for cooking as only lard and other. The dotted line represents an odds ratio of 1 , which corresponds to no association. $\mathrm{Cl}$, confidence interval.

ethnicity as an explanatory variable (ie ethnicity is statistically significantly related to elements of health behaviour after adjustment for the socioeconomic factors).

The utility and interpretation of ethnicity as a health determinant has long been debated in the scientific literature, with several models put forward to explain the relationship between ethnicity and health. ${ }^{20}{ }^{21}$ There is evidence that genetic factors may have a more important role in explaining differences in health of different populations. For example nicotine dependence and smoking persistence are heritable, and are determined by a complex interplay of polygenic and environmental influences to a degree larger than previously thought..$^{22}$ Nevertheless, explanations attributing health disparities to genetic differences between various minority and majority groups have been increasingly challenged due to the recognition that ethnicity is more of a social, than a biological construct. ${ }^{23}{ }^{24}$

Another set of theories proposes health behaviour variations among ethnic groups as an explanation for health disparities. ${ }^{21}$ Diet, exercise and smoking are well-known health determinants of major importance, and have been shown in our previous paper to substantially differ between Roma and non-Roma. ${ }^{14}$
However, health and health behaviour are influenced by more distal health determinants such as education, income, occupation and other dimensions of the socioeconomic status. ${ }^{25}{ }^{26}$ The socioeconomic model holds that ethnic health disparities are confounded with SES disparities, ${ }^{21}$ therefore all ethnic health variations must be adjusted for the widest possible range of socioeconomic factors. If significant ethnic differences in health behaviour not explicable by SES remain, as in this case, then the partial mediation model holds, and additional factors related to ethnicity can be hypothesised as health determinants. This was the case in an intervention study in a Slovenian Roma population, which revealed that smoking is a strong part of the cultural, ethnic and individual identity of the Roma to the extent that even children smoke. Advice from a doctor to quit smoking is usually not followed, and the attempts to quit are usually unsuccessful. The study found that the Roma hold a tenacious belief that the harmful effects of smoking are in the hands of destiny and do not associate their smoking-related illnesses with the habit. ${ }^{27}$

The material interpretation of health inequalities assigns a considerable part of ethnic health variations to differential access to material conditions such as food, shelter, access to

Table 2 The association between socioeconomic status, Roma ethnicity and health behaviour

\begin{tabular}{|c|c|c|c|}
\hline & \multicolumn{3}{|l|}{ Odds ratio* $(95 \% \mathrm{Cl})$} \\
\hline & Daily smoking & $\begin{array}{l}\text { Consumption of fresh fruits } \\
\text { less than weekly }\end{array}$ & $\begin{array}{l}\text { Using only lard as fat } \\
\text { for cooking }\end{array}$ \\
\hline Equivalent monthly income $\dagger$ & 0.94 (0.92 to 0.97$)$ & $0.95(0.87$ to 1.0$)$ & $0.96(0.87$ to 1.1$)$ \\
\hline \multicolumn{4}{|l|}{ Education } \\
\hline Primary only & 1.0 (reference) & 1.0 (reference) & 1.0 (reference) \\
\hline Secondary without leaving certificate & $0.77(0.63$ to 0.95$)$ & $0.55(0.38$ to 0.79$)$ & $0.48(0.35$ to 0.65$)$ \\
\hline $\begin{array}{l}\text { At least secondary education with leaving } \\
\text { certificate }\end{array}$ & $0.48(0.39$ to 0.59$)$ & $0.33(0.21$ to 0.51$)$ & 0.25 (0.16 to 0.37$)$ \\
\hline \multicolumn{4}{|l|}{ Employment } \\
\hline Active worker & 1.0 (reference) & 1.0 (reference) & 1.0 (reference) \\
\hline Unemployed & $1.4(0.96$ to 1.9$)$ & $1.3(0.73$ to 2.5$)$ & $2.1(1.2$ to 3.7$)$ \\
\hline Pensioner & $0.70(0.54$ to 0.92$)$ & $1.9(1.2$ to 3.0$)$ & $1.6(1.0$ to 2.4$)$ \\
\hline Disability pensioner & $0.52(0.38$ to 0.70$)$ & $1.4(0.81$ to 2.5$)$ & $1.3(0.84$ to 2.1$)$ \\
\hline Other inactive & $0.80(0.63$ to 1.0$)$ & $1.3(0.80$ to 2.0$)$ & $1.7(1.1$ to 2.5$)$ \\
\hline Living in Roma settlements & $1.6(1.3-2.0)$ & $2.1(1.5-2.9)$ & $1.5(1.1 .-2.0)$ \\
\hline
\end{tabular}


services, etc. ${ }^{28} 29$ Evidence was found in the present study to support this model, as income was strongly related to health.

According to the psychosocial model, ethnic health behaviour variations could be attributed to stress due to the discrimination and social exclusion resulting from holding a low socioeconomic position. ${ }^{21} 3031$ Although discrimination against the Roma both in everyday life and more specifically in healthcare have been reported, ${ }^{32}{ }^{33}$ publications have not been encountered on perceived stress among them. Increased odds of smoking among Roma settlement dwellers even after adjustment for SES in the present study, and the high prevalence of smoking among pregnant Roma women might in part be attributed to such psychosocial factors. ${ }^{914}$ Data on the early disadvantages of Roma children and the life course perspective would also deserve attention when the psychosocial explanation of the health behaviour of Roma are further elaborated. ${ }^{34-36}$

Socioeconomic status in the present study could not fully explain the increased odds of lard use for cooking, as well as low consumption of fresh fruits and vegetables in the Roma. Psychosocial health determinants seem unlikely to account for these increased odds, therefore other determinants including rurality, traditions and beliefs should be considered as additional contributing factors. ${ }^{37-39}$

The present findings have shown that there is no unique model for the different aspects of the complex relationship of Roma ethnicity and health. The neo-material model, ${ }^{29}$ the structural-constructivist model according to which our "ability to control disease and death are distributed according to resources of knowledge, money, power, prestige, and beneficial social connections', ${ }^{40}$ and other models that emphasise both psychological and sociocultural factors ${ }^{21}$ have different explanatory powers for the associations between ethnicity and specific dimensions of health.

One limitation of the present study may lie in the methodology. Two dimensions of health were studied: health status and health behaviour. The answers provided about health status might reflect a more global subjective rating of health and wellbeing, whereas the answers about specific health behaviours were more clearly defined. Consequently, the former may be more likely to be affected by reporting biases such as negative response style, which might themselves be associated with socioeconomic status and ethnicity. This potential bias may explain why socioeconomic status was found to fully mediate health status, but not health behaviours. Nevertheless, the question about functionality was much more specific than the question about self-reported health, and the results about the two dimensions of health status were consistent. Furthermore, only income, education and employment were used as socioeconomic factors in the analysis. Including additional socioeconomic factors in the model might have shown a stronger mediational effect for socioeconomic status on heath behaviours.

The present study suffers from the obvious limitation that it is not representative of the overall Hungarian Roma population. It did not include those Roma that are assimilated with the majority population to various degrees. However, given the unwillingness of many people to self-define their ethnicity as Roma, this is a constraint that will be very difficult to overcome. As the Roma Health Survey involved the most disadvantaged section of the Roma population, the present results apply to the group whose needs are the most important to understand from a policy perspective.

Finally, as in any survey based on self-report, the data on diet must be interpreted with caution. Nevertheless, the probability

\section{What is already known on this subject}

Ethnicity is a well-established determinant of health behaviour and health status.

\section{What this study adds}

- The results highlight that socioeconomic status is a very strong determinant of the health of people living in Roma settlements.

- The study shows that the association between Roma ethnicity and health status is fully mediated, and the association between Roma ethnicity and health behaviour is partially mediated by the socioeconomic status.

of information bias in case of the simple questions used to assess the frequency of fruit and vegetable consumption and about the types of fat used for cooking is much less than in a detailed dietary questionnaire.

Although the evidence gathered so far on the nature, magnitude and causes of health inequities between Roma and non-Roma has already been sufficient to have immediate policy implications, the contextual factors are of fundamental importance to design and implement efficient programmes to increase the health of Roma people. Decent housing, education and employment should be the first marks on the long road to empower Roma people to improve their health. Understanding the role of their traditions and culture as health determinants may help increasing speed and avoiding dead ends along this road.

Acknowledgements: The contribution of fieldworkers and other study personnel is gratefully acknowledged, as is the support of the Ministry of Health, Ministry of Environment, and Ministry of Education of Hungary.

Funding: The National Health Interview Survey, 2003, was funded by the Hungarian Ministry of Health in the framework of the National Public Health Programme. The Roma Health Survey was funded from Hungarian research grants from the National Research and Development Program (NKFP-1B/0013/2002) and the Ministry of Environment (KvH-96/167/2000). This project was funded by the National Scientific Council on Health (ETT: 331/2006).

Competing interests: None

Ethics approval: Ethical Committee of the Hungarian National Scientific Council on Health.

\section{REFERENCES}

1. Kósa K, Ádány R. Studying vulnerable populations. Lessons from the Roma minority Epidemiology 2007:18:290-9.

2. Trask JW. The significance of the mortality rates of the colored population of the United States. Am J Public Health 1916;6:254-60.

3. Smith DG, Wentworth D, Neaton JD, et al. Socioeconomic differentials in mortality risk among men screened for the Multiple Risk Factor Intervention Trial, 2: black men. Am J Public Health 1996;86:497-504.

4. Smith DG, Neaton JD, Wentworth D, et al. Mortality differences between black and white men in the USA: contribution of income and other risk factors among men screened for the MRFIT. Lancet 1998:351:934-9.

5. Borrell LN. Racial identity among Hispanics: implications for health and well-being. Am J Public Health 2005:95:379-81.

6. Race, Ethnicity and the Health of Americans. ASA series on how Race and Ethnicity Matter. July 2005. www2.asanet.org/centennial/race_ethnicity_health.pdf (accessed 10 March 2008).

7. Department of Health. Ethnicity. www.doh.gov.uk/ethdevlist3.htm laccessed 19 August 2000)

8. Balarajan R. Ethnic differences in mortality from ischaemic heart disease and cerebrovascular disease in England and Wales. BMJ 1991;302:560-4.

9. Kósa K, Lénárt B, Ádány R. Health status of the Roma population in Hungary [in Hungarian]. Orv Hetil 2002;143:2419-26. 
10. Koupilova I, Epsteina H, Holcik J, et al. Health needs of the Roma population in the Czech and Slovak Republics. Soc Sci Med 2001;53:1191-204.

11. Ambrus P, Csepe P, Forrai J, eds. Minorities, communication, health [In Hungarian] Budapest: Medicello Ltd. - Soros Foundation, 2002.

12. Farkas I. The Monkey That Does Not See. www.errc.org/cikk.php?cikk=1940. Roma Rights Quarterly (accessed 6 November 2007).

13. Hajioff S, McKee M. The health of the Roma people: a review of the published literature. J Epidemiol Community Health 2000;54:864-9.

14. Kósa Z, Széles G, Kardos L, et al. Health of the inhabitants of Roma settlements in Hungary - a comparative health survey. Am J Public Health 2007;97:853-9.

15. Smith GD. Learning to live with complexity: ethnicity, socioeconomic position, and health in Britain and the United States. Am J Public Health 2000;90:1694-8.

16. Boros J, Csizmadia P, Hermann D, et al. National Health Interview Survey 2003, Hungary-Executive Update. Budapest, Hungary: Johan Béla National Center for Epidemiology, 2004. www.oek.hu/oekfile.pl?fid=533 (accessed 30 October 2007).

17. Boros J, Csizmadia P, Hermann D, et al. Questionnaire of the National Health Interview Survey 2003. Budapest: Johan Béla National Center for Epidemiology, 2004. The European Health Interview \& Health Examination Surveys Database: hishes.iph.fgov.be/index.php?hishes = his_questionschis header_id = 132\&print $=$ 1 \&view mode $=$ survey (accessed 5 November 2007).

18. Bruin $\overline{\mathbf{A}}$, Picavet HSJ, Nossikov A. Health interview surveys towards international harmonization of methods and instruments. Copenhagen: World Health Organization Regional Office for Europe, 1996.

19. Baron RM, Kenny DA. The moderator-mediator variable distinction in socia psychological research: conceptual, strategic, and statistical considerations. J Pers Soc Psychol 1986:51:1173-82.

20. Kaplan JB, Bennett T. Use of race and ethnicity in biomedical publication. JAMA 2003;289:2709-16

21. Dressler WW, Oths Ks, Gravlee CC. Race and ethnicity in public health research: models to explain health disparities. Annu Rev Anthropol 2005;34:231-52.

22. Lermann CE, Schnoll RA, Munafo MR. Genetics and smoking cessation improving outcomes in smokers at risk. Am J Prev Med 2007:33(6 Suppl):S398-405.

23. Cooper R, David R. The biological concept of race and its application to public health and epidemiology. J Health Polit Policy Law 1986;11:97-116.

24. Krieger N. Shades of difference: theoretical underpinnings of the medical controversy on black/white differences in the United States, 1830-1870. Int J Health Serv 1987:17:259-78

25. Krieger N, Williams DR, Moss NE. Measuring social class in US public health research: concepts, methodologies, and guidelines. Annu Rev Public Health 1997; 18:341-78
26. Galobardes B, Shaw M, Lawlor DA, et al. Indicators of socioeconomic position. J Epidemiol Community Health 2006;60:7-12.

27. Petek D, Rotar PD, Svab I, et al. Attitudes of Roma toward smoking: qualitative study in Slovenia. Croat Med J 2006:47:344-7.

28. Kawachi I, Subramanian SV, Almeida-Filho N. A glossary for health inequalities J Epidemiol Community Health 2002;56:647-52.

29. Lynch JW, Smith GD, Kaplan GA et al. Income inequality and mortality: importance to health of individual income, psychosocial environment, or material conditions. BMJ 2000;320:1200-4

30. Krieger N, Sidney S. Racial discrimination and blood pressure: the CARDIA Study of young black and white adults. Am J Public Health 1996;86:1370-8.

31. Marmot M, Wilkinson RG. Social determinants of health. Oxford: Oxford University Press, 1999.

32. European Commission. Directorate General for Employment and Social Affairs. The situation of Roma in an enlarged European Union. Luxembourg: Office for Official Publications of the European Communities, 2004. ec.europa.eu/employment social/ fundamental rights/pdf/pubst/roma04 en.pdf. (accessed 11 April 2008).

33. Danova-Russinova S. Ambulance not on the way: the disgrace of health care for Roma in Europe. Budapest: European Roma Rights Center, 2006. www.soros.org/ initiatives/health/focus/roma/articles publications/publications/ambulance 20061004 (accessed 11 April 2008).

34. Kertesi G, Kézdi G. The Roma children of the transformation recession [in Hungarian] Budapesti Munkagazdaságtani Füzetek BWP 2005/5. www.econ.core.hu/doc/bwp/ bwp/Bwp0505.pdf (accessed 18 December 2007).

35. EU Monitoring and Advocacy Program. Equal access to quality education for Roma. Monitoring Reports. Open Society Institute, 2007. www.soros.org/initiatives/ roma/articles publications/publications/equal 20070329 (accessed 18 December 2007).

36. Barker DJP. Mothers, babies and health in later life. Edinburgh: Churchill Livingstone, 1998.

37. Probst JC, Moore CG, Glover SH, et al. Person and place: the compounding effects of race/ethnicity and rurality on health. Am J Public Health 2004;94:1695703

38. Hjelm KG, Bard K, Nyberg P, et al. Beliefs about health and diabetes in men of different ethnic origin. J Adv Nursing 2005;50:47-59.

39. Jasti S, Siega-Riz AM, Bentley ME. Dietary supplement use in the context of health disparities: cultural, ethnic and demographic determinants of use. J Nutr 2003;133:2010S-3S.

40. Phelan JC, Link BG. Controlling Disease and Creating Disparities: A fundamental cause perspective. J Gerontol B Psychol Sci Soc Sci 2005:60(Spec No 2):27-33. 